$\begin{array}{lcccr}\begin{array}{l}\text { T H E A R C H I V E } \\ \text { VOL. LIX }\end{array} & \text { O F } & \text { M E C H A N I C A L } & \text { E N G I N E E R I N G } \\ \text { 10.2478/v10180-012-0001-6 } & & \text { Number } 1 \\ \text { Key words: mechatronics, object design, algorithm, conceptual design } & \end{array}$

OLEKSANDR UZUNOV*

\title{
THE CYCLIC-MODULAR APPROACH TO SIMULATION AND DESIGN OF THE MECHATRONIC OBJECTS
}

\begin{abstract}
The cyclic modular approach is proposed for mechatronic object design. The approach is based on a new conceptual model of the object and a new algorithm of its design. The model consists of invariant and changeable parts. The parts have a hierarchical structure. The proposed algorithm allows for creating the object from the basis principle to the construction step by step. It makes it possible to design an adequate object in all forms of its representations: structure, schematic diagram, mathematical model and construction. Each of these forms has an invariant part, i.e. the structure of the functioning process of the object. Application of the proposed approach reduces the time needed for the object design.
\end{abstract}

\section{Motivation}

Simulation and creation of mechatronic objects are complicated tasks [1]. The reasons for the complication are the features of such objects: variety, complexity and transience of working processes, dependence of object's characteristics on coordination of work of object elements, difficulty or impossibility of analytical prediction of the characteristics and others. The creation of such an object is time-consuming. To increase efficiency of a new object creation it is necessary to take an adequate approach and improve algorithms of design. The approaches and the algorithms are based on an accepted conceptual representation of the object.

The analysis shows that the known conceptual representations of an object reflect the content of the object's components and interactions between the components on the most general level. In these representations, the concep-

* Department of Applied Fluid Dynamics and Mechatronics, Mechanical Engineering Institute, National Technical University of Ukraine "Kiyv Polytechnic Institute”, Av. Peremogy 37, Kiyv, Ukraine; e-mail: uzu@ rambler.ru 
tual model includes the classes and the objects, the modules and processes, the logical and physical structures, the static and dynamic states (Fig. 1) [2].

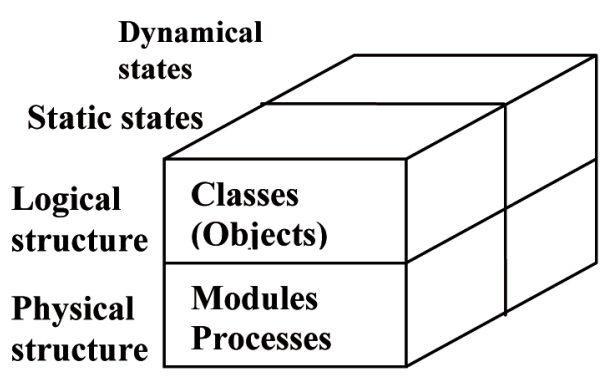

Fig. 1. The model of the object in object oriented approach of design [2]

The analysis of the known approaches shows that they include all necessary stages: analysis, specification, conceptual design, concrete design, mathematical model building, simulation, testing and others. At the same time, the application of these approaches takes a lot of time. The reasons are the difficulties of: understanding of working processes, building an adequate mathematical model, obtaining desired characteristics and so on. The approaches determine the stages and the order of their application in the design. The approaches are widely in use, but they cause difficulties in obtaining an adequate mathematical model of the object $[3,4,5,6]$. From our point of view, it is caused by discordance between the conception of model's construction and building of real objects. At the same time, the author has an experience in making the connection between individual stages of the object creation more accurate [7]. It reduces the time of object design. The additional effect can be obtained if this experience is extended on all stages of design.

The purpose of this work is to reduce the time required for mechatronic objects design. This purpose is achieved by determination and application of connection between the functioning, building and properties of the object.

\section{Design of mechatronic objects by using the cyclic-modular approach}

The analysis of mechatronic objects shows that there are interconnections between the composition of the elements inside the object, functioning and properties of the object. The connections are the following. 1. Functioning determines composition of the object. 2. There is a similar base for the functioning and the composition of the object. This is the closed structure of the process of the function execution. Realization of the function leads to obtaining the property. 3 . There is a similarity in composition and functioning of the object. It is a hierarchical and modular organization. 4. The object 
has invariant and changeable parts. The invariant part is represented by the structure of the process of the object functioning, and the changeable part is represented by the set of object's properties. These connections are used in engineering design of the mechatronic objects. The basis for creation of the object is a conceptual model of the object and an algorithm of its design.

\section{Conceptual model of the object}

The model represents invariant and changeable parts. The invariant part is represented by the structure of the object, which remains constant during its development and through the whole life cycle. The changeable part is represented by the object states. The states of the object are changed in the design process and are represented by a set of object properties. For instance, such properties are: the obtained principle of operation, the property to possess a set of functions, the property to possess a concrete structure of functioning, and so on. Each of object states is represented in the model of object by a single layer. The proposed conceptual model of the object has a multi-layered structure (Fig. 2). This model is named the developing model.

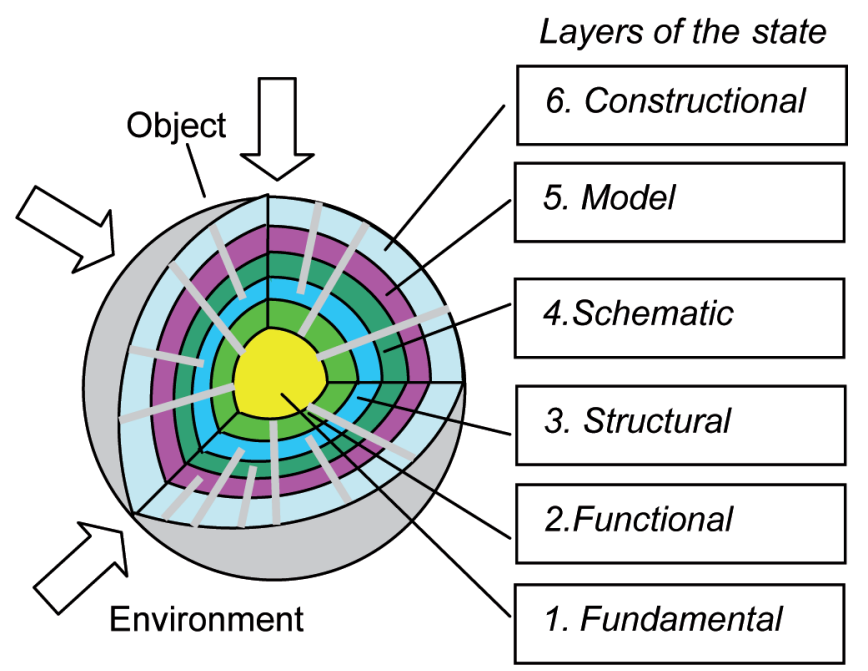

Fig. 2. Representation of the developing object in environment of design

Its kernel is the principle of operation that is the base of the object work. The kernel is covered by layers. Each of them corresponds to a concrete state of the object development. There are the following states: functional, structural, schematic, model, constructional. Each of the object layers has a hierarchical module structure. The object states are represented in the layers by concrete means. For example, words are used to describe the principle of operation, a 
functional diagram is used to represent the set of functions and their interaction, graphical symbols of elements are used to represent schematic diagram and so on. In the proposed model, there are connections between different representations of these means. These connections are marked by conversions from layer to layer in radial direction in the object conceptual model. For example, hydraulic throttle is represented by: a graphical symbol in the schematic layer, a mathematical formula in the model layer, construction in the constructional layer. It allows us to keep the invariant part in different layers. The invariant part is formed in the structural layer. A graphical symbol is used to show the structure of the functioning process - an arrow with a mark. Each of the arrows indicates a single action in the functioning process. The marks indicate content of the actions. The structure is represented as a chain of arrows. There are specific rules for forming this layer. For example, the structure must have a closed form. The fulfillment of these rules guarantees that the structure is structurally and logically adequate for the functioning process of the object. Forming the layers on the basis of this structure guarantees that the model is adequate in each layer. For example, an adequate mathematical model is obtained by replacing the structure actions with their mathematical descriptions. The closed structure is also the indicator of the module. The modules also have hierarchical structure. The modules of lower level are based on a single closed structure. The modules of higher level include the inner closed structures. The layers of the model have a modular composition.

\section{Algorithm of the object forming}

The proposed algorithm of the object forming is based on its developing model. The algorithm has a multi-loop structure (Fig. 3). The detailed description of the logic block shows the logic of switching to each next loop of the design process (Fig. 4). Each loop corresponds to the layer of model that represents a state of the object. The start of the algorithm is initiated by the demand of an object with the set of properties. Further, specification of the object is formulated, and the set of individual requirements for the object is obtained. Then, the initial loop is started. This loop corresponds to forming the kernel that is the principle of the object operation. The chosen principle initiates the next loop - specification of the object functions. This layer is complete when the functional diagram of the object work is ready. This event initiates the next loop - forming the structure of the functions realization process. The layer is complete when the detailed structure of the functioning is obtained. In the two loops, the schematic diagram and the mathematical model are formed on the basis of the structure. Further, 
the simulation is used. The results are: the values of element parameters that provide the required characteristics of the object. In the next loop, the composition of the object is formed. According to the algorithm, the design result is the object with the set of required properties. The created object satisfies the demand that was the reason for the object engineering.

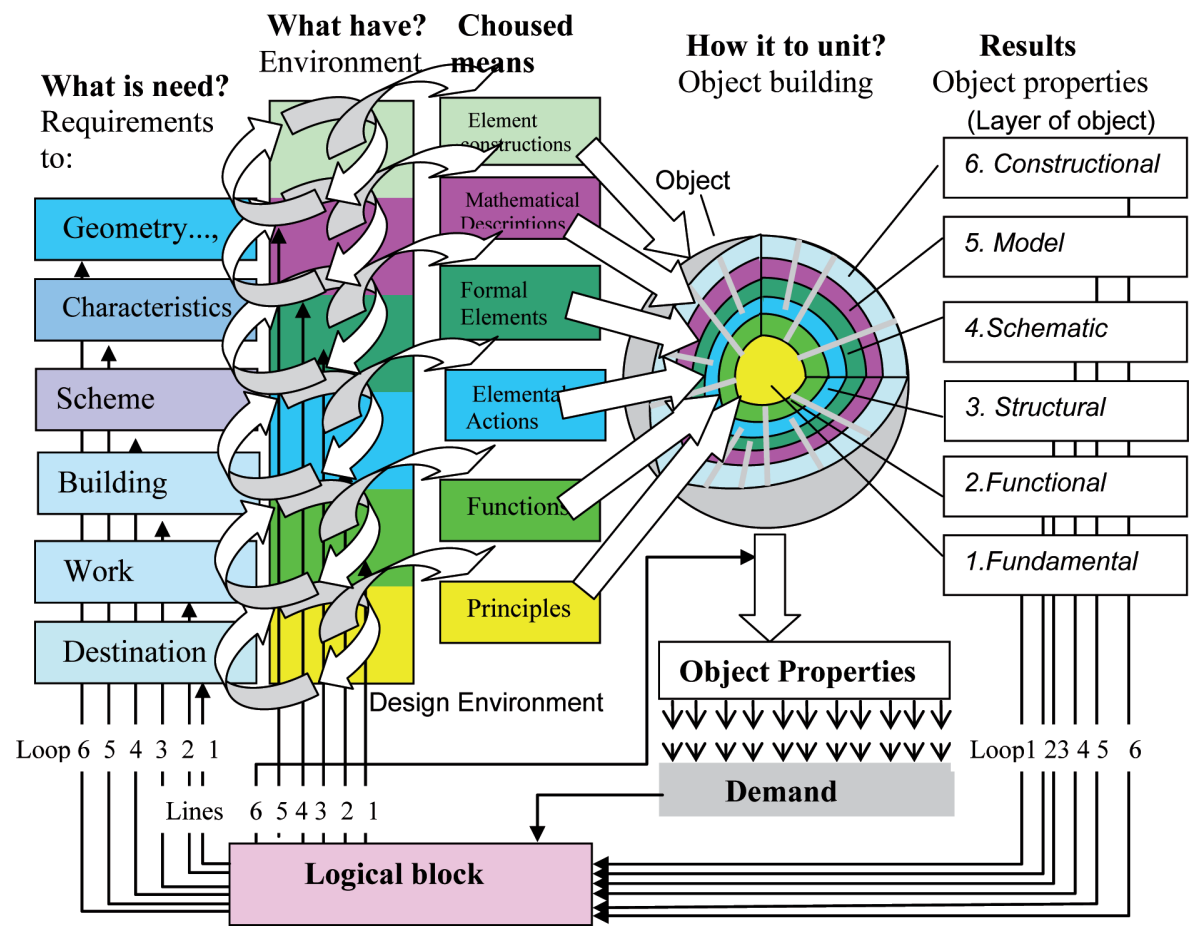

Fig. 3. The algorithm of the object design on the base of the developing model of the object

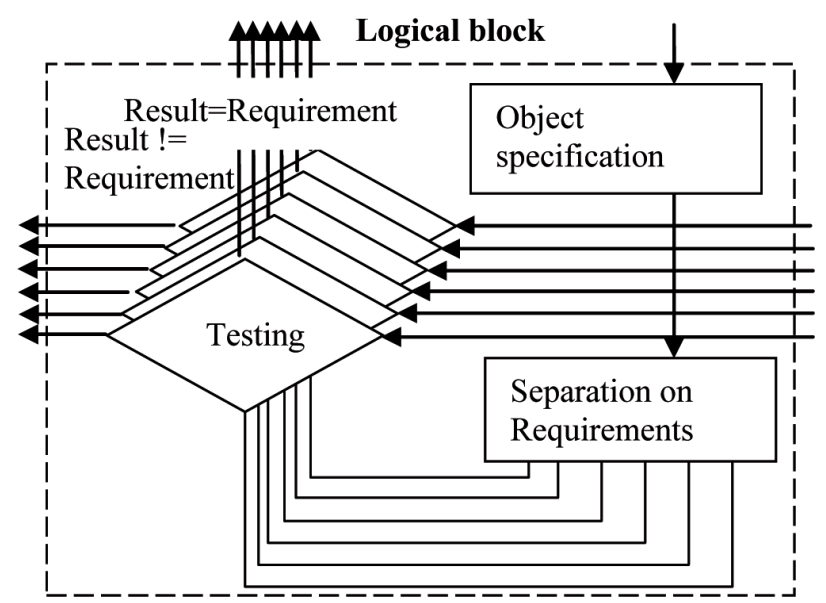

Fig. 4. Internal organization of the logical block 
The application of the developing model of an object, the algorithm and cyclic-modular approach, increases the efficiency of mathematical model building and object design due to:

- the use of rules of connections between the process of the object functioning, its structure, and its properties;

- ensuring structural and logical adequateness of model;

- the use of succession between layers;

- the use of modular building of the object.

Application of the proposed approach makes the process of object creation several times less time-consuming.

\section{Detailed representation of the cyclic-modular approach with an example of design of servo drive with mechanical and hydraulic components}

There is a demand for a servo drive in order to position a rod (Fig. 5). The input control signal is a mechanical displacement. The hydraulic energy must be used to provide output power higher then the input. The stroke of the rod is $0.25 \mathrm{~m}$. The tracking error must be less then $0.2^{*} 10^{-3} \mathrm{~m}$. The mass in motion is $8.5 \mathrm{~kg}$. The pump pressure is $9 \mathrm{MPa}$.

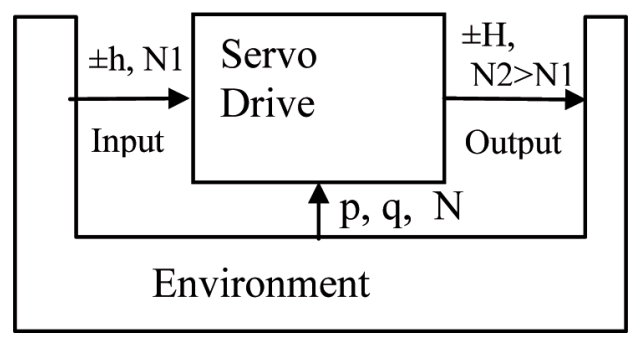

Fig. 5. Destination of the servo drive

To accomplish this task, the developing model of the object and the proposed algorithm were used (Fig.2, 3, 4).

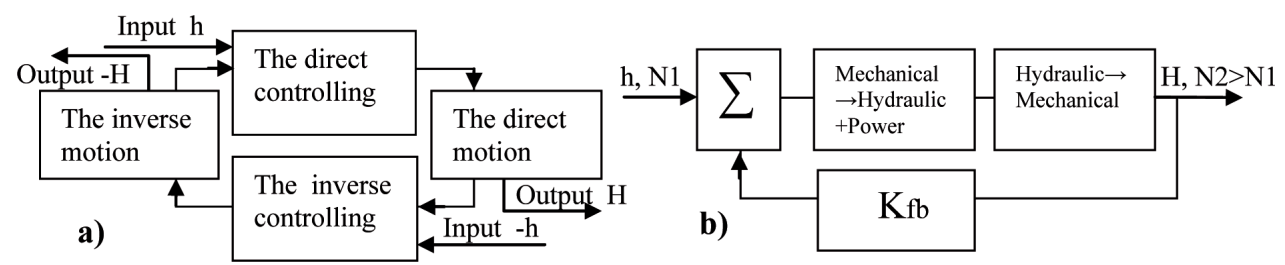

Fig. 6. The functional diagram of the double action drive (a) and functional diagram of single action drive (b) 
Initially, the drive demand is converted into the drive specification. The specification was separated according to the requirements for the drive.

In the first loop, we make the choice of the principle of operation of the drive. This principle is the following. The point-to-point motion of the output element of the drive is the result of positioning of input element that leads to imbalance of forces on the output element due to the throttle control of hydraulic energy. The new position of the output element is the result of balancing the forces. The second loop is started (Fig.3) if the principle is really the basis of the drive with the required predestination.

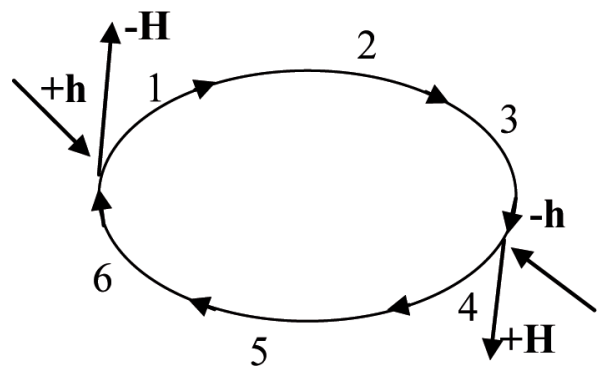

Fig. 7. The structure of the process of double action drive $( \pm \mathrm{h} \longrightarrow \pm \mathrm{H})$

The second loop. The functional layer of the drive is formed. To provide the required predestination on the basis of the principle, the drive has to execute the following functions: the control of direct motion; the direct motion; the control of inverse motion; the inverse motion. Then, the function process of the direct and inverse motions is specifyed by the content and the order of actions. Executing the functions in the required order leads to the realization of the principle. The result of readiness of the layer is the functional diagram (Fig.6). Then next loop is started.

The third loop. The structural layer is formed. In this layer, each function is represented in the form of a closed structure or structures. One closed structure represents one property of the drive. The structure is closed because it is necessary to repeat execution of the function. On the other hand, the closed form of the structure produces the set of requirements concerning the content and the sequence order of actions in the work process. The requirements are the following. The structure must include all needed actions. Each direct action of the structure must be complemented with an inverse action. The logical order of actions must lead to realization of the function. The sequence order of actions must form the coupling of the structure. If the structure satisfies the requirements, the description is logically and structurally adequate for the function process.

According to these requirements and to the functional diagram, the layer with the closed structures of drive work was represented. The common 


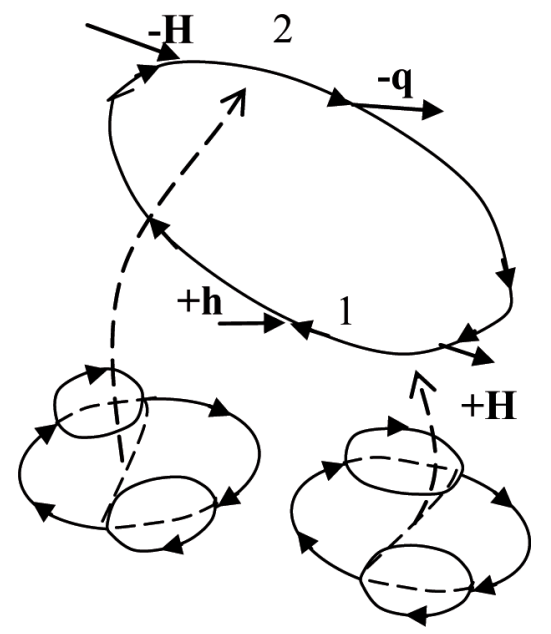

Fig. 8. The scheme of obtaining the hierarchical structure of the single action drive $(+h \rightarrow \pm H)(1$ - substructure of direct action $(+\mathrm{h} \rightarrow+\mathrm{H}) ; 2$ - substructure of restoring action $(-\mathrm{H} \longrightarrow-\mathrm{q}))$

structure of the double-action drive includes the following actions and transformations: 1 - turning off inverse motion; 2 - turning on direct motion; 3 - transformation of direct displacement of the input element to direct displacement of the output element $(\mathrm{h} \rightarrow \mathrm{H}) ; 4$ - turning off direct motion; 5 - turning on inverse motion; 6 - transformation of inverse displacement of the input element to inverse displacement of the output element $(-\mathrm{h} \rightarrow-\mathrm{H})$ (Fig. 7).The structure is built in a hierarchical form. This hierarchy can be detected in a detailed structure. The closed structure is also the indicator of the module. The structure can contain modules of different levels. The common structure of the work process of the double-action drive has the structures of the following modules: the drive of double action $( \pm \mathrm{h} \rightarrow \pm \mathrm{H})$; the drive of single action of direct motion $(+\mathrm{h} \rightarrow+\mathrm{H})$; the drive of single action of inverse motion $(-\mathrm{h} \rightarrow-\mathrm{H})$; the transducer of displacement to velocity $(\mathrm{h} \rightarrow v)$; the transducer of liquid flow to velocity $(\mathrm{q} \rightarrow v)$. In the considered drive, there are two similar structures of modules of single-action drives: $(+h \rightarrow+H),(-h \rightarrow-H)$. The difference between these modules consists in their application - the first module is used to provide direct motion, the second one is used to provide inverse motion. It means that this type of module is used twice. Multiple utilization of identical modules reduces the time of the drive design. The effect is multiplied if the module can be detected in initial stages of the design process. In the proposed approach, the modules can be detected in the structural layer before the schematic diagram is obtained.

In the next step, the details of the common structure were determined. As an example, the detailed module structure of a single-action drive of 
direct motion is represented in Fig. 8. This structure includes two parts. First part accords with execution of direct motion, and second part accords with restoring the initial state. The detailed representation of the first part shows the contents and sequence order of single actions and transformations (Fig. 9).

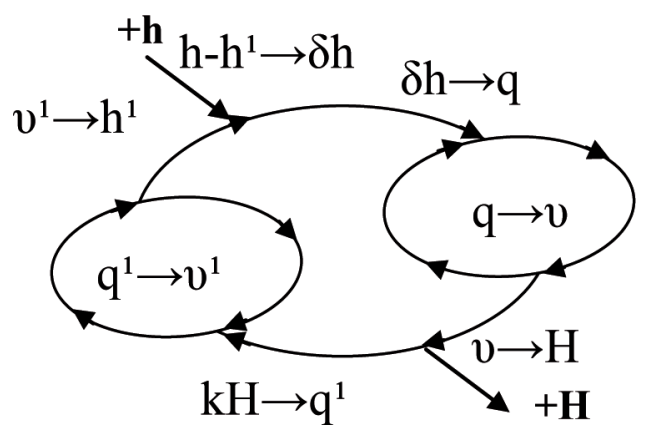

Fig. 9. The substructure of the process of direct action of the single action of drive $(+h \rightarrow+H)$

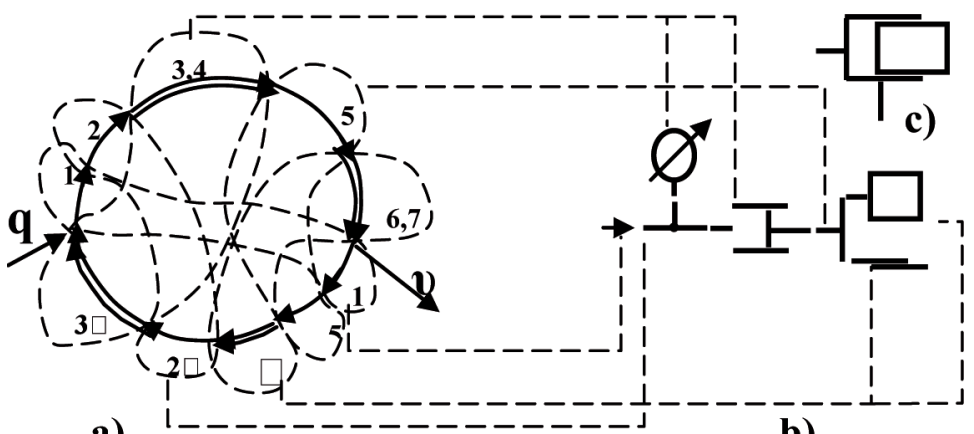

a)

b)

Fig. 10. The detailed module structure of the process of the function $(\mathrm{q} \rightarrow v)(\mathrm{a})$, the conversion to the schematic diagram of this module (b) and it graphical symbol (c)

The fourth loop. The schematic diagram of the drive was obtained. To do so, the required actions of the detailed module structures were replaced by the schematic symbols of physical elements (formal means). At this step, it was necessary to take into account that each means is executing two mutually antithetic actions: direct action and inverse action. For example, there is the formal means - the pressure tank. This means needs to accumulate hydraulic energy. The tank action is determined by the condition of its application. The tank will charge under the condition that the pressure outside of the tank is higher then the pressure inside. This is the direct action. If the pressure outside of the tank is lower than inside, the tank executes the inverse action - discharging. All required formal means are used in accordance with duality of actions of the elements. Then, schematic diagram of drive is obtained by 
the way of uniting the schematic symbols of formal means. The order of symbol connections is determined by the order of the actions running in the structure of the work process. As an example, there is the representation of the conversion of the first-level substructure - the transformation of the process $(\mathrm{q} \rightarrow v)$ into its schematic diagram (Fig.10a, b). This module has also an aggregate graphical symbol (Fig.10c). It is used to simplify the representation of the schematic diagram of complicated systems. There are also representations of the substructures conversion of the second and third levels (Fig.11, 12). The third-level module has an aggregate representation also (Fig.13). The schematic diagram of the double-action drive was obtained also in this manner. This schematic diagram is represented in an aggregate form (Fig.14). This technique of conversion provides the transfer of the structure into the schematic diagram. It is important to note that the obtained schematic diagram implements the structure of the process of functioning of the object. In the case when the schematic diagram of the drive is obtained, the layer is ready.

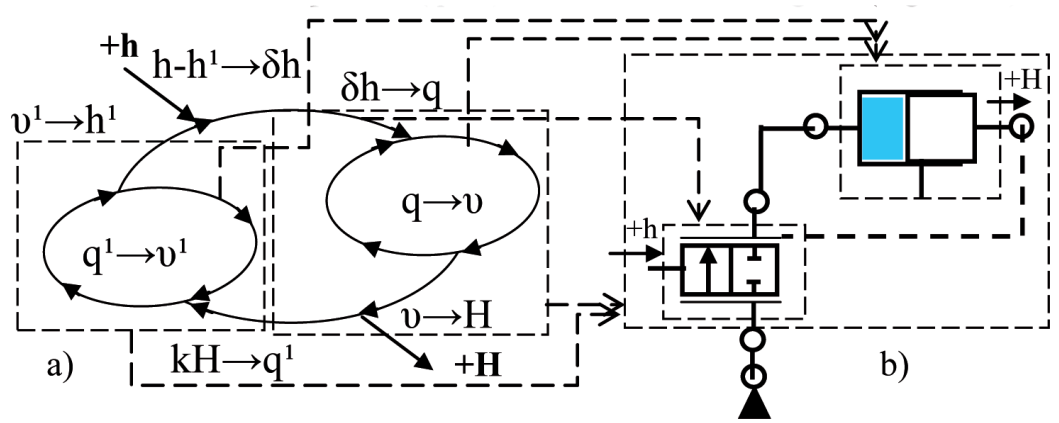

Fig. 11. The conversion of the substructure of the process of direct action of single action of drive $(+h \rightarrow+H)$ (a) to the schematic diagram of this module (b)

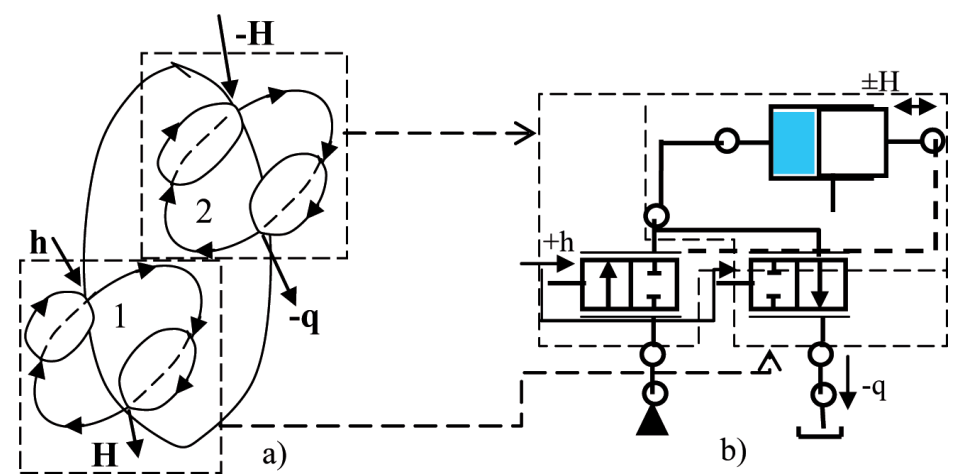

Fig. 12. The conversion of the structure of the single action drive $(+h \rightarrow \pm H)$ (a) to the schematic diagram of this module (b). 1 is substructure of direct action; 2 is substructure of restoring action 


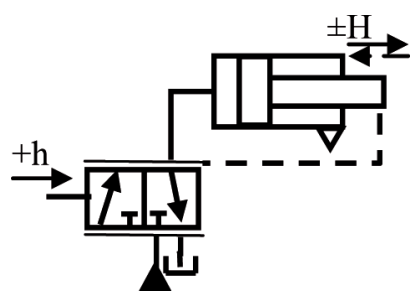

Fig. 13. The schematic diagram of single action drive $(+h \rightarrow \pm H)$

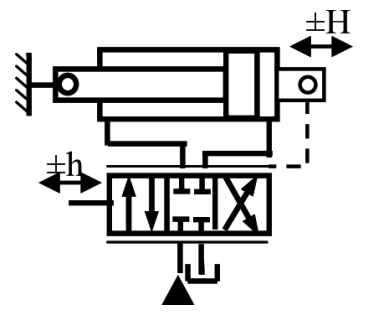

Fig. 14. Schematic diagram of double action servo drive $( \pm \mathrm{h} \rightarrow \pm \mathrm{H})$

In the fifth loop, the mathematical model was obtained and the work processes in single modules and in whole drive were simulated. To do it, each action of all formal means of the schematic diagram was replaced by its mathematical description. The mathematical model was represented with a chain of mathematical descriptions of single actions. This conversion is illustrated by an example of transformation of the module $(\mathrm{q} \rightarrow v)$ (Fig.15). The chain of descriptions corresponds to the process of functioning. The applied technique preserves the structure of the functioning process due to one-toone transformation of the schematic diagram to the mathematical model. It guarantees that the mathematical model is adequate for the physical process of the drive.

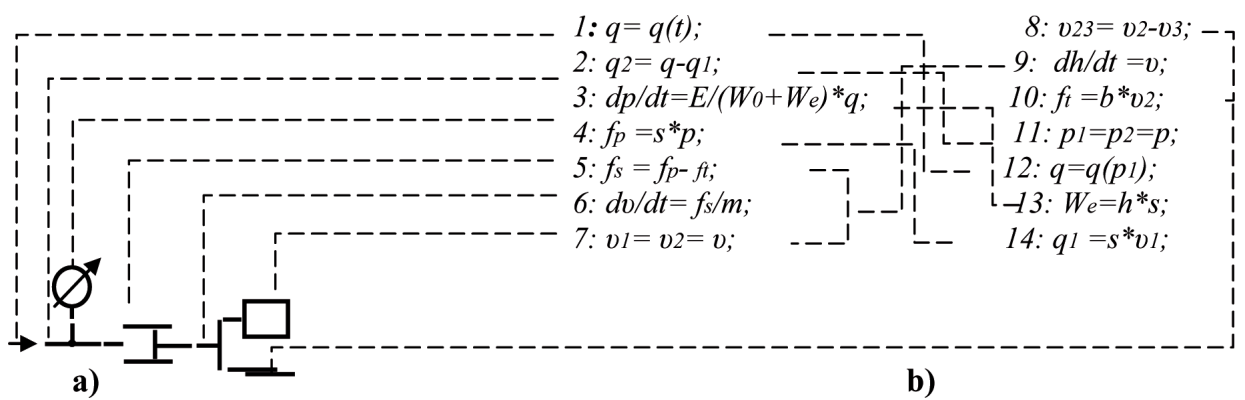

Fig. 15. The schematic diagram of the module $(\mathrm{q} \rightarrow v)$ (a) and their conversion to the mathematical model (b) 
The mathematical model is used to simulate the work of separate modules and the whole drive. As an example, the graphics of the work process in the double-action drive without feedback is represented (Fig.16). The simulation allowed us to adjust the drive parameters and to achieve the required characteristics in the autotrack regime (Fig.17). The servo drive ensures an acceptable tracking error. The parameters of the drive are the following. The rod has the length of throttle gap $2 * 10^{-3} \mathrm{~m}$, the diameter of the piston is $45^{*} 10^{-3} \mathrm{~m}$, the diameter of the rod is $30 * 10^{-3} \mathrm{~m}$.

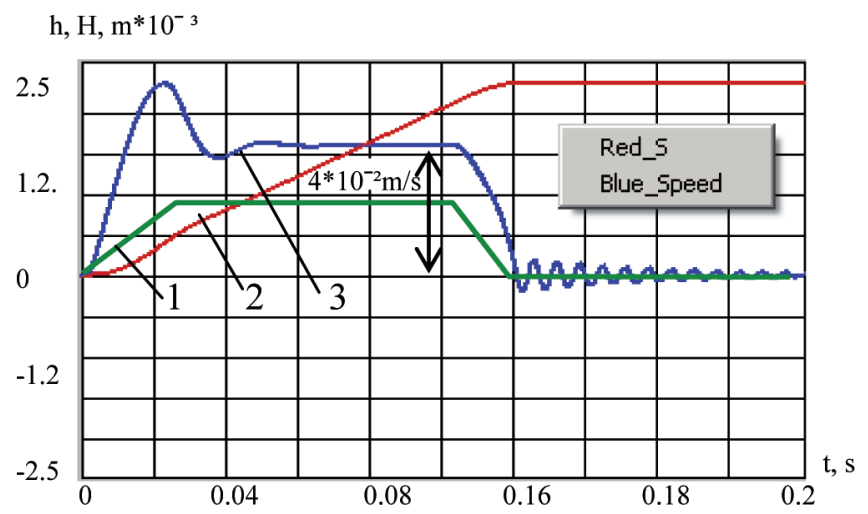

Fig. 16. Graphics of work processes in double action drive without feed back. 1 is the slide displacement, 2 is the rod displacement, 3 is the rod velocity
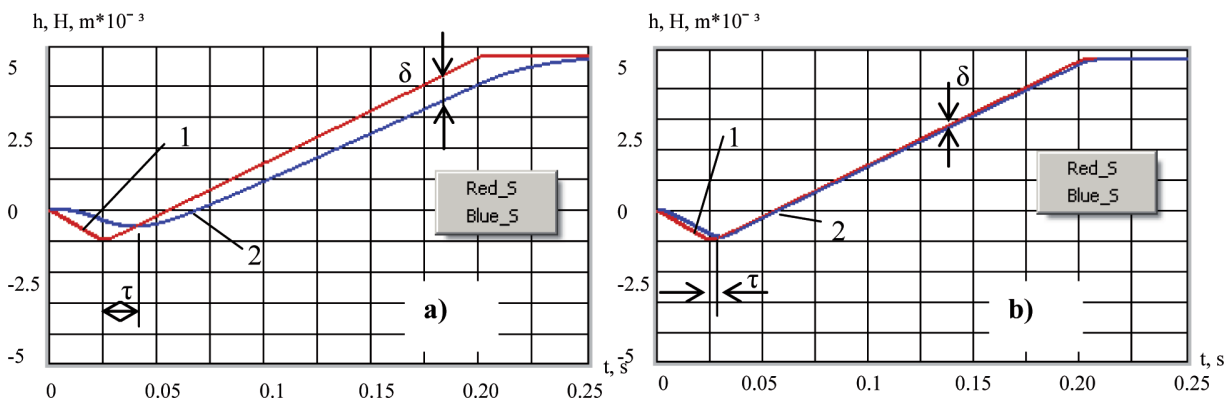

Fig. 17. Graphics of work processes in double action servo drive in autotrack regime before

(a) and after (b) parameters adjusting. 1 is the input displacement of slide, 2 is the output displacement, $\delta$ is the tracking error, $\tau$ is displacement lag

In the sixth loop, the construction of the drive was obtained. To do so, each schematic symbol of a physical element (formal mean) of the schematic diagram was replaced by the corresponding construction. The geometrical sizes of constructions are set in accordance with the values of parameters of simulation. The connections between elements were made on the basis of the schematic diagram. Then the elements were rotated as required for 
their correct work. After that, all element constructions were united into the construction of the drive with the body (Fig.18).

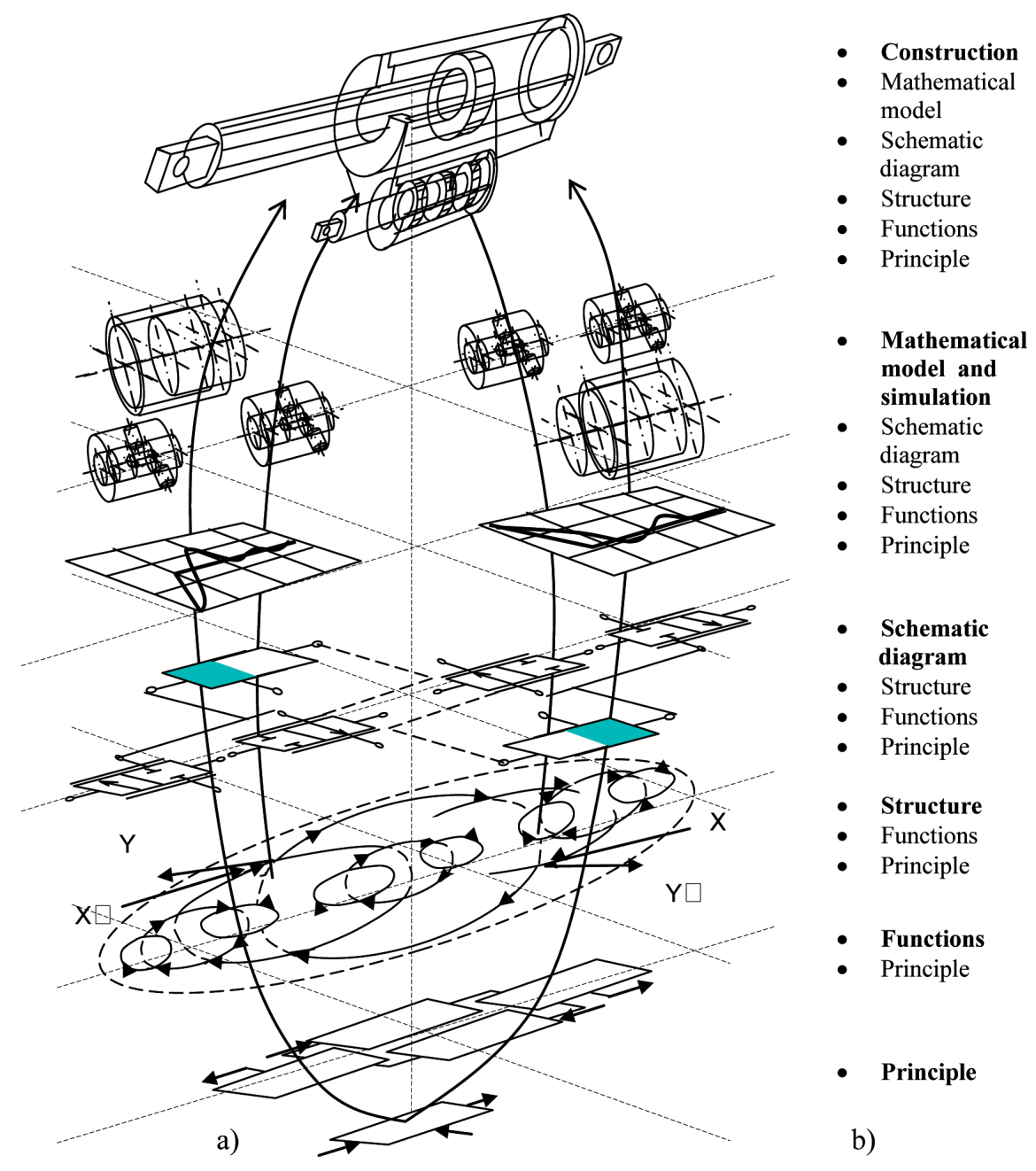

Fig. 18. The development of servo drive in design process. The content of the layers of the object (a) and the set of the obtained properties (b)

Using the sequence of the loops and applying the manner of conversion at all stages of the object design, one preserves the permanent structure of the process of functioning of the drive. As the result, the drive with the set of properties and the required characteristics is obtained and the time needed for design is reduced. 


\section{Conclusion}

The proposed cyclic modular approach of a mechatronic object design is based on a new conceptual model of the object and a new algorithm of its design. The conceptual model is represented in a sandwich-type form with many layers, and has invariant and changeable parts. It allows formalizing the design process. The proposed model brings about a new understanding of the design process. The design process is considered as forming of the object properties and the object changing is considered as development. The conversions from one layer to another preserve the structure of the functioning process in all layers of the object model. In the result, an adequate object model is obtained in the process of object creating and the time of the design process is reduced.

Manuscript received by Editorial Board, October 06, 2011;

final version, February 16, 2012.

\section{REFERENCES}

[1] Иринг Ю.: Проектирование гидравлических и пневматических систем. - Л.: Машиностроение. Ленингр. отд-ние, 1983, 363ц.

[2] Буч Г.: Обьектно-ориентированное проектирование с примерами применения. - М.: Конкорд, 1992 с. 519.

[3] The engineering design process/Atila Ertas, Jesse C. Jones, John Wiley\& Sons, Inc. 1993. $-515 p$.

[4] Integrated systems and design, Editors: Reiner Dudziak, Carsten Kohn, Raivo Sell, TUT Press, Tallinn, 2008, 208 p.

[5] Stania M., Stetter R.: Mechatronics engineering on the example of a multipurpose mobile robot, Solid State Phenomena, Mechatronic Systems and Materials III Trans Tech Publication, Volumes 147-149 (2009), p. 61-66.

[6] VDI 2206: Design methodology for mechatronical systems, Beuth, Berlin, 2004.

[7] Uzunov O.: The computer model building approach for the work processes in mechatronics objects. 8-th International Workshop on Research and Education in Mechatronics REM 2007, 14-15 June 2007, Tallinn, Estonia, TUTPRESS, p.224-228.

Podejście cykliczno-modularne w projektowaniu obiektów mechatronicznych

$$
\text { Streszczenie }
$$

Zaproponowano zastosowanie podejścia cykliczno-modularnego w projektowaniu obiektów mechatronicznych. Podejście jest oparte na nowym modelu pojęciowym i nowym algorytmie projektowania. Model składa się z części zmiennych i niezmiennych. Części modelu mają strukturę hierarchiczną. Proponowany algorytm umożliwia tworzenie obiektu krok po kroku wychodząc od 
jego podstawowej zasady działania. Pozwala to na projektowanie odpowiedniego obiektu we wszystkich formach jego reprezentacji, którymi są: struktura, schemat graficzny, model matematyczny i konstrukcja. Każda z tych form ma część niezmienną, tzn. strukturę procesu funkcjonowania obiektu. Zastosowanie proponowanego podejścia pozwala ograniczyć czas potrzeby na projektowanie obiektu. 